\title{
A formação de profissionais de saúde para atuação na rede de frio e salas de vacinas
}

\author{
The training of health professionals to work in the cold chain and \\ vaccination rooms
}

\author{
La formación de profesionales de salud para actuación en la \\ cadena de frío y salas de vacunación
}

\begin{abstract}
REDE DE FRIO: FUNDAMENTOS PARA A COMPREENSÃO DO TRABALHO. Silva MN, Flauzino RF, Gondim GMM, organizadoras. Rio de Janeiro: Coordenação de Desenvolvimento Educacional e Educação a Distância, Escola Nacional de Saúde Pública Sergio Arouca, Fundação Oswaldo Cruz/Editora Fiocruz; 2017. 256 p. ISBN 978-85-8432-020-2.
\end{abstract}

doi: 10.1590/0102-311X00160418

Instituído em 1973, na esteira do sucesso da campanha de erradicação da varíola, o Programa Nacional de Imunizações (PNI) brasileiro é reconhecido nacional e internacionalmente como uma das mais bem-sucedidas ações em Saúde Pública, tendo contribuído significativamente para a redução da morbi-mortalidade por doenças imunopreveníveis no país. Nos últimos 12 anos, oito novas vacinas (rotavírus, pneumocócica conjugada 10-valente, meningocócica $\mathrm{C}$ conjugada, hepatite A, varicela, HPV, inativada de pólio e tríplice acelular do adulto - dTpa) foram incorporadas nos calendários de imunização de rotina do PNI. Além disso, houve ampliação da recomendação de vacinação para grupos etários não tradicionalmente considerados alvo de ações de imunização (adolescentes, gestantes e adultos em geral). Além da vacinação de rotina, o PNI realiza também campanhas anuais de vacinação (influenza, pólio e multivacinação), bem como ações de imunização para contenção de surtos e epidemias (como por exemplo, o sarampo na Região Nordeste, em 2013-2014, e na Região Norte, em 2018; e a febre amarela na Região Sudeste, em 2017-2018). Desde sua criação, o programa cresceu muito em tamanho e complexidade, exigindo dos profissionais de saúde que nele atuam, capacitação e atualizações técnicas contínuas, não só referente aos imunobiológicos (vacinas e soros) - suas indicações, seus efeitos (desejados e adversos), seu manuseio e conservação, mas também sobre a vigilância em saúde e a organização dos serviços.

O livro Rede de Frio: Fundamentos para a Compreensão do Trabalho 1 é uma resposta à demanda por profissionais qualificados para atuação na área. Não se trata de um referencial teórico e operacional sobre a estrutura, logística, funcionamento e gestão da rede de frio para imunobiológicos. O conteúdo do livro é muito mais amplo do que seu título sugere, abordando o conceito de saúde e doença, o sistema de saúde, a vigilância em saúde, as doenças imunopreveníveis e os imunobiológicos.

O primeiro capítulo (Um Pouco de História: Evolução das Concepções de Saúde, Doença e Cuidado) apresenta a evolução do conceito saúdedoença e seus determinantes, desde os povos primitivos (pré-história) e civilização greco-romana, passando pela idade média até a modernidade. O segundo capítulo (Políticas Públicas de Saúde e a Organização do SUS) traz um breve histórico dos modelos assistenciais e políticas 
públicas de saúde no Brasil, no século XX, que levaram à construção do Sistema Único de Saúde (SUS); os princípios e diretrizes do SUS e a organização dos serviços de saúde. O terceiro capítulo (Introdução à Vigilância em Saúde: Vigilância Epidemiológica, Vigilância Sanitária, Ambiental e Saúde do Trabalhador) aborda a implantação, organização e estrutura da vigilância em saúde no Brasil; os objetivos, responsabilidades e ações de cada um dos campos de atuação da vigilância; assim como os conceitos de risco e vulnerabilidade em saúde. O quarto capítulo (Conhecendo a Epidemiologia) mostra a importância da epidemiologia enquanto ferramenta para traçar o perfil de saúde da população. O quinto capítulo (Indicadores de Saúde e Sistemas de Informação em Saúde: Instrumentos para Analisar a Saúde da População) apresenta os principais indicadores de morbidade e mortalidade e alguns indicadores utilizados pelo PNI; os principais sistemas de informação em saúde (Sistema de Informação de Agravos de Notificação - SINAN; Sistema de Informações sobre Mortalidade - SIM; Sistema de Informações sobre Nascidos Vivos - SINASC; Sistema de Informações Hospitalares do SUS - SIH/SUS; e Sistema de Informação Ambulatorial do SUS - SIA/SUS), seus objetivos e instrumentos de coleta de dados. O sexto capítulo (Vigilância Epidemiológica) discute a vigilância epidemiológica, seus objetivos, ações, fontes de dados e métodos. O sétimo capítulo (Vigilância das Doenças Imunopreviníveis) aborda as principais doenças imunopreveníveis, seus sinais e sintomas, formas de transmissão, impacto epidemiológico, vigilância e estratégia de controle. São ainda apresentados conceitos básicos em epidemiologia das doenças transmissíveis. O oitavo capítulo (Os Imunobiológicos na Proteção da Saúde: Conhecendo sua História) apresenta um histórico do desenvolvimento de algumas vacinas disponíveis. O nono e último capítulo (Noções de Imunologia: Sistema Imunológico, Imunidade e Imunização) traz conceitos básicos de imunologia, fundamentais para a compreensão do mecanismo de ação dos imunobiológicos.
O texto, didático, de fácil leitura, passeia por temas complexos de maneira simples, introduzindo conceitos fundamentais e convidando o profissional/leitor à uma reflexão e compreensão mais ampla e crítica sobre o exercício de suas atividades e sua inserção no sistema de saúde. A obra constitui importante instrumento de formação para todos os profissionais de saúde do SUS, não apenas daqueles que atuam na rede de frio e salas de vacinas.

Escrito por profissionais com reconhecida experiência na área e publicado pela Editora Fiocruz, em parceria com a Coordenação de Desenvolvimento Educacional e Educação a Distância, Escola Nacional de Saúde Pública Sergio Arouca, Fundação Oswaldo Cruz (CDEAD/ENSP/ Fiocruz), a obra "integra uma estratégia ampla de formação profissional que inclui, entre seus objetivos, propor aos trabalhadores, nos serviços ou no meio acadêmico, leituras e debates sobre os diferentes campos do conhecimento que sustentam a rede de frio de imunobiológicos" (contracapa), constituindo significativa contribuição na área.

Ana Marli Christovam Sartori 1

1 Faculdade de Medicina, Universidade de São Paulo, São Paulo, Brasil.

anasartori@gmail.com

1. Silva MN, Flauzino RF, Gondim GMM, organizadoras. Rede de frio: fundamentos para a compreensão do trabalho. Rio de Janeiro: Coordenação de Desenvolvimento Educacional e Educação a Distância, Escola Nacional de Saúde Pública Sergio Arouca, Fundação Oswaldo Cruz/Editora Fiocruz; 2017. 